\title{
Research on the Differentiation of TV Programs at Home and Abroad
}

\author{
Weiliang Zhao ${ }^{1,}$ a \\ ${ }^{1}$ Baicheng Normal College, Media Institute, Baicheng, Jilin, China \\ a13769461@qq.com
}

Keywords: TV Program, Difference, Host; Guests.

\begin{abstract}
China's TV programs have been localized. In this paper, the domestic and foreign TV programs of the local transformation of differentiation research. China's TV programs are divided into two major plates, the first is a comprehensive program, from CCTV TV to local TV stations, all contain different information. The second plates are emotional communication programs, which are not only emotional, but also incorporate some communication skills. The host uses a variety of ways and techniques to relax the audience. Foreign TV interview programs are divided into daytime TV talk show and night TV talk show. The audience of the daytime program is mainly housewives, and the content is novel and interesting. The main audience of the night program is male, and the purpose of watching is to relieve the pressure. Foreign TV talk shows are classified as popular current events, funny programs, communication programs, emotional programs, programs for special audiences.
\end{abstract}

\section{The Overall Difference}

\section{A. The General Characteristics of TV Talk Shows Abroad}

TV talk show is to foreign culture as the focus, covering books, television and so on, invite one or more guests, guests of the high quality, therefore, show charm is also very high, the program creation process more careful, pay more attention to details. There are two characteristics of the foreign talk program: first, the positioning of the talk program is high-end atmosphere, or easy to understand, attracting audience from the content of the problem. Second, the host needs to have the good strain ability. TV talk show is foreign to the profit center, the profit is talked, sensitive topic is more popular, entertainment became the talk show in a beautiful landscape, no entertainment is not a selling point, is the cornerstone of the whole show entertainment.

B. The General Characteristics of Domestic TV Talk Show

China's TV talk shows generally choose social hot information in topic selection, and Chinese programs are mainly represented by guests. China TV talk shows including the following three characteristics: first, to give guests more about space, second, good question, the questions the way is more Chinese traditional cultural values, fit third, final comment, experience for their inner host, make an emotional communication with the guests and the audience. Rendering the atmosphere.

\section{The Specific Differences}

\section{A. Analysis from Topic Selection}

There is a big difference between the western culture and political thought, in the selection of topic also has a great difference, in terms of the freedom of speech, many western countries than domestic open, they dare to talk to the national political, small to personal feelings and life. China is the focus of traditional cultural exchanges, therefore, will be constrained in the selection process of programming, the extreme topic will be filtered out, and suggestions of educational topics will be selected programs, the purpose is to promote the development of harmonious society. 


\section{B. Analysis from the Host}

The host is the core character of the whole column. The quality of a TV program is closely related to the level of the host. Host abroad has strong charisma, some viewers like the host, just to watch the program. Chinese presenters pay attention to the appearance of the image, the style of the host pays attention to emotional communication, so the domestic and foreign hosts in the style is very different.

\section{Analysis from Guests}

The choice of guests plays a vital role in the quality of programs, guests can bring the whole performance of the atmosphere of the show, to choose the guests according to the different location of the column, China guests would suggest on show but not problems are solved. In foreign countries, guests dare to face up to problems, start from reality, find problems, and use practical actions to solve problems.

\section{From the Audience Analysis}

The audience abroad can contrast atmosphere and drive the rhythm of the whole scene. The audience's overall quality is high, will participate in the program to come, foreign audience can on-site interaction, active speech, can truly integrate into the environment. In China, the audience is reluctant to interact, and when the point of view is expressed, the audience will not show their position, slightly rigid.

E. From the Creative Mode and Operating Mechanism of the Program Analysis

The domestic and foreign TV talk show creation mode and operation mechanism is different, the foreign TV talk show planning time needs about 20 days of discussion, the topic before broadcast, the most important is the host of the program to participate in the topic, express their opinions and suggestions. After the topic is determined, the host will interview the star, and the interview is related to life and emotion. In the program, the audience will tell their own wishes or difficulties to the column group, and then the column group will help the audience to solve the difficulties encountered, the desire to achieve. The whole telephone conversation program shows a flexible atmosphere from music to pictures, which will not make the audience tired, but also enrich the content of the program. In China, in order to promote the atmosphere, the director will deliberately arrange the audience, or invite some acquaintances to support the scene. This arrangement will let the program go on orderly, but destroy the most sincere side of the program, this deliberate arrangement is not conducive to the overall effect of TV talk show.

\section{Reflections on the Differences of TV Programs at Home and Abroad}

\section{A. Stiff Topic}

The topic of Chinese TV talk shows is so stiff that it leads to the simplification of the program, so it is not as good as the foreign programs, and the audience rating has been affected. China, as a country paying attention to tradition and harmony, is a little more serious. However, Chinese TV programs can learn to innovate, find out our own ideas, cannot always imitate foreign countries, we should improve the domestic audience's happiness index by mining their own characteristics.

\section{B. Authenticity of Guest Language}

China TV shows, people do not want to participate in the recording of the program to tell the truth, some people just perfunctory, with the development of society, each person's degree of education continues to improve, to a higher level of speech. In China's TV talk show, we can increase the interactive game, let the audience and guests participate in it, and create an atmosphere together. The game can be the appropriate theme, finish the game after the summary of the whole process. Through these practices to enhance the quality of the program, breaking the deadlock now.

\section{Through the Introduction of Foreign TV Programs, and Promote Comprehensive and Coordinated China TV Industry Sustainable Development}

A. In Order to Establish the Public as the Center of the Production Concept

China is in an important period of social transformation, the civic consciousness, rights 
consciousness and participation consciousness unceasing enhancement, the television media as the most widely used and most influential, the most audience communication platform, firmly establish the audience centered production concept, put down the shelf down to earth, the one way push indoctrination, which is centered on me, has won the audience and won the market for the audience centered two-way interaction. Practice shows that the production of television programs only adhere to the audience as the center of broadcast television audience as the concept of God, to meet the needs of the audience as the first priority, reflection of social reality, with the spirit of the times, leading the public topic, creating public space, build communication platform, the service life of the people, to achieve public dreams, social transfer positive the energy, the dissemination of mainstream values, in order to make television programs to the audience's attention and attention, realize the organic unity of social and economic benefits.

B. TV Program Innovation Incentive Guarantee Mechanism

To promote the innovation of TV program, we must solve the problem of innovation power from the mechanism, and establish and perfect the incentive mechanism of TV program innovation. From the government level, the urgent need to establish a sound system of TV program policies to encourage innovation, the establishment of government support for the innovation of TV programs of the special fund, set up to encourage the innovation of TV programs in recognition of the incentive mechanism, vigorously to create a television program to encourage and support innovation in the external environment; from the TV station level, the urgent need to establish a safeguard mechanism to support innovation, set up the program the innovation of special funds to carry out extensive program innovation activities, provide platform for the transformation of innovation, improve innovation consciousness, vigorously create and encourage and support the innovation of TV programs of the internal environment, to enhance the capability of independent innovation Chinese TV program to provide a strong guarantee.

C. Television Broadcast Separation System and Deepen the Reform

The responsibilities, rights and obligations of TV Zhibofenli reform involves broadcast institutions and production enterprises, involved in program production, broadcast and trading behavior, involving government, broadcasters and production business interests, deepen Zhibofenli reform is an urgent need for the government departments to create harmonious and orderly, fair and healthy development of the TV industry environment. In addition, actively explore the mechanism of entry and exit of television, allowing between TV stations to achieve inter regional integration of resources through channels Zhibofenli, promote economic development lags behind regional TV stations and local city and county TV broadcast advertising quality and management level, thus forming the development of television channel resource collection effect, realizes the television industry do bigger and stronger goals.

D. Construction of TV Integrated Marketing Communication System

In the program planning stage, simultaneously to develop the program marketing strategy and a clear path to program promotion, advertising and subsequent market development; in the production stage, give full consideration to TV, network, mobile phone and other media broadcast features and profit model, to meet the different needs of media communication programs; early in the programme. Make full use of various media publicity, the formation of information flow and strong public opinion field, clearly convey the purpose of the program, meaning and characteristics, to maximize attract public attention, arouse people watching desire; during the broadcast, the media continue to maintain strong, timely and appropriate social topics, build a social media platform public opinion, to attract, retain and expand public attention to maximize. In addition, the TV station should also do a good job in social public relations work, through supporting public welfare undertakings, participate in major social activities, shaping social image, and improve social awareness and reputation. With the implementation of the integrated marketing communication system of TV programs, the unification of TV program viewing and word of mouth, the win-win of social and operational benefits can be realized. 


\section{Conclusion}

Chinese TV talk shows are more about the imitation of foreign programs. We should fundamentally solve the problem of Chinese TV talk shows. For in the development of the China TV program, which is a process of growing up, only to face the disadvantages, continuous innovation, improve the overall level of the program, Chinese TV talk show can have a qualitative leap. We should absorb the essence of foreign TV programs reasonably and show the value of TV programs truly. We should find out the national characteristics in the course of the topic selection, focus on the social beneficial information, and let the TV talk show in China create a new height. Differentiation strategy is an important means to promote program development, build program brand, enrich television culture, and flourish cultural development. In the television practice in the future. We will each link strategy into television production. Starting from the public opinion, really serve the people, to do the program form loved by the people.

\section{References}

[1]Hu Zhifeng,Yang Chenghu. Observation and Reflection on the Innovation of Chinese TV Programs [J]. Modern Communication, 2011(06);

[2]Xie Yungeng,Wang Caiping.Chinese TV Entertainment Market Report [J]. News Circles,2005 (08);

[3]Wang Heite,Wang Xizi. Chinese TV Program Type System Analysis [J]. Chinese TV, 2011 (06);

[4]Zhang Bo.Present Situation of China TV Program Originality and Promotion Strategy[J].China Radio and TV Academic Journal ,2013(10);

[5]Yang Hui, Tang Jiancong. Construction of Chinese Television Humanistic Value [J]. TV Research, 2013(04);

[6]Zheng Tianfang. On the Breakthrough Strategy of Localization of Chinese TV Programs in the Context of Globalization[J]. News Communication, 2013(07). 